Reviews in Digital Humanities • Vol. 3, No. 2

\title{
Review: Literature in Context
}

Mattie Burkert ${ }^{1}$, Tonya Howe ${ }^{2}$, John O'Brien ${ }^{3}$, Miranda Hughes ${ }^{4}$, Roopika Risam ${ }^{4}$, Jennifer Guiliano ${ }^{5}$

${ }^{1}$ University of Oregon, ${ }^{2}$ Marymount University, ${ }^{3}$ University of Virginia, ${ }^{4}$ Salem State University, 5IUPUI

Published on: Feb 14, 2022

DOI: 10.21428/3e88f64f.72a81b60

License: Creative Commons Attribution 4.0 International License (CC-BY 4.0). 


\section{Project}

Literature in Context: An Open Anthology of Literature in English

\section{Project Directors}

Tonya-Marie Howe, Marymount University

John O’Brien, University of Virginia

Project URL

http://anthology.lib.virginia.edu

\section{Project Reviewer}

Mattie Burkert, University of Oregon

\section{Project Overview}

\section{Tonya-Marie Howe and John O'Brien}

College and secondary school teaching in the humanities depends on accurate, welledited texts. Yet we live in a world mediated by the digital, which has shaped our reading practices in ways both positive and negative. Students are unlikely to know how to judge the quality or authority of texts that they find on Google, which is a primary point of access, and the classroom experience can suffer as a result. Freely available full-text archives are rarely edited and contain minimal, if any, contextual annotations; neither do they clearly indicate provenance. Conversely, digital archives may be focused on single authors and edited to a highly scholarly degree, making them challenging for students to engage with as basic reading editions. Literature in Context ( $\mathrm{LiC}$ ) is designed to provide at least a partial remedy to this situation.

A slow digital humanities project that makes available reliable, annotated digital texts of frequently-taught literary works in English, LiC also involves students and faculty in the process, with a primary academic goal of enhancing digital information literacy. Students can read online and view annotations in pop-ups, accompanied where possible with facsimile page images; in PDF, with annotations as footnotes; collaboratively, with a native Hypothesis layer; in ePub on their e-readers; or in facultydefined coursepacks, which can handle excerpts of longer texts as well as entire works, functioning ideally as agile replacements for print anthologies.

Digital literature anthologies currently in existence are rare and based on the logic of print. They may address price and accessibility but make it impossible to take 
advantage of rich media content and interactivity, excerpting and constructing themed coursepacks, or facilitating student-faculty collaboration on the construction of new materials integrated seamlessly into the born-digital project. By involving students in the production of texts in the anthology, this project offers a model for a kind of critical making that can be integrated into the classroom in a variety of ways. Students who sign a release form are named as contributors in the project, making traditionally invisible labor visible. $\mathrm{LiC}$ is an intervention in scholarly publishing, an exercise in collaborative critical making, and an alternative model for text-based open educational resources (OER).

LiC uses eXist-db, a flexible open-source database platform designed to work with XML. Materials are coded in XML standardized according to Text Encoding Initiative guidelines. Application code and texts are stored on GitHub for others to access and use, with images hosted on Amazon Web Services. The site includes a space for pedagogical materials. Currently, the anthology incorporates work by 25 authors, largely from the long 18th century, the area of content expertise of the creators (example texts are Mary Wollstonecraft's Vindications, Ben Franklin's Autobiography, and Laurence Sterne's Sentimental Journey). As the project develops from proof-ofconcept, we anticipate further systematizing the XML, adding additional texts, refining the use of linked data and headnotes, registering the project with open educational resources (OER) repositories, and seeking a press imprint as well as further funding. While the primary audience for LiC is secondary- and college-level students, we note that the project is also global, with users from around the world. We also aim this project at faculty who work in digital humanities pedagogy and who wish to explore digitization projects with students, as well as faculty who want to develop more agile, responsive, and accessible mini-anthologies suited specifically to course content.

This project grew out of two similar independent projects developed by John O'Brien at the University of Virginia and Tonya Howe at Marymount University. With Christine Ruotolo of University of Virginia Libraries, we combined efforts and applied for a grant from the National Endowment for the Humanities (NEH). In addition to receiving funding from the $\mathrm{NEH}$, the project is also supported by Marymount University and the University of Virginia. Christine Ruotolo specializes in data management and the digital library; Tonya Howe, focuses on digital pedagogy and 18th-century British literature; and John O'Brien, concentrates on literary history of the long 18th century. Coming at this project from a collaborative perspective, we seek to incorporate the missions of two very different institutions. Our web developer, Winona Salesky, has 
expertise in XML, XSLT, and XQL, in addition to possessing humanistic domain knowledge. We have also presented widely and written about the Enlightenment goals of the project for Eighteenth-Century Common.

\section{Project Review}

\section{Mattie Burkert}

Teachers of public domain texts often weigh the pedagogical advantages of classroom editions against the barriers posed by rising textbook costs. Literature in Context (LiC) helps fill the need for open-access primary source digitizations edited to a high scholarly standard. With support from the NEH Office of Digital Humanities, the LiC team has developed more than 80 teaching editions of English and American texts published from the late 17th through the early 19th century, as well as the technical framework to source additions to its catalog from the community. Even as an initial proof of concept, LiC promises to become a vital resource for teaching historical literature, digital textual editing, and information literacy.

The title "Literature in Context" refers to the historical contexts non-specialist readers need to engage with literary texts. Each edition includes annotations, often enriched with images and links, that explain archaic terms, gloss allusions, and provide background information. These annotations pop up rather than opening a new tab, fostering a deep reading practice that embraces the browser's affordances while resisting its potential for distraction. Biographical headnotes are also available for several authors.

LiC offers multiple options for classroom integration. Instructors can assemble custom coursepacks; invite students to read and annotate collaboratively using the built-in Hypothes.is layer; or print individual texts as PDF or EPUB files with annotations rendered as footnotes. Each edition includes TEI/XML files, page images, editorial statements, and lists of primary sources, making visible elements of textual materiality and scholarly labor that digitization sometimes obscures-and, by extension, providing students with key tools to assess documents' provenance and reliability. Students can also develop information literacy skills experientially by curating new content for the site, a process modeled in the available editions and facilitated by the published technical documentation and sample assignment prompts.

The LiC catalog emphasizes frequently taught authors like Aphra Behn, Jonathan Swift, Daniel Defoe, Olaudah Equiano, Phyllis Wheatley, William Wordsworth, and Jane 
Austen. The selection is diverse within the traditionally close parameters of the 18thcentury canon, which remains shaped by the same histories of oppression on which the field now turns its gaze. The project's community-sourcing ethos, however, gives it the power to expand the field's limits. LiC will soon publish the first-ever digital edition of The Woman of Colour (1808), a novel that has recently become a classroom staple despite being available in only one critical print edition. To represent the long 18thcentury Atlantic world more fully, LiC should prioritize incorporating more Indigenous and Caribbean voices and continue growing the collection's strengths in women's literature and Black diasporic writing.

The project team plans a series of technical improvements, including further development of a promising linked data feature. The website would also benefit from more accurate search and sort algorithms and from accessibility features in line with WAI best practices around page structure, text resizing, and image description. By maximizing the site's usability, the team can ensure this project reaches the learners and makers who will sustain it moving forward. 